\title{
Entomopathogenic efficacy of the endophytic fungi: Clonostachys sp. and Beauveria bassiana on Tuta absoluta (Meyrick) (Lepidoptera: Gelechiidae) larvae under laboratory and greenhouse conditions
}

Fadhela Mohamed Mahmoud ${ }^{1,2^{*}}$ (D), Rachida Bendebbah ${ }^{2,3}$, Bouchra Benssaci ${ }^{2,3}$, Fethia Toudji ${ }^{4}$, Lamia Tafifet ${ }^{1,3}$ and Zoulikha Krimi ${ }^{2,3}$

\begin{abstract}
Background: Endophytic fungi are excellent sources of new natural bioactive products with potential for exploitation in medical, agricultural, and industrial fields. Beneficial effects of endophytes are not only limited to promoting plant growth, but also to react as plant protection agents against phytopathogenic microorganisms and plant pests. The tomato leaf miner, Tuta absoluta (Meyrick) (Lepidoptera: Gelechiidae) is one of the main tomato pests in South America and in the Mediterranean basin.

Results: In the present work, the effectiveness of two endophytic fungi Clonostachys spp. and Beauveria bassiana were tested against T. absoluta larvae. Evaluation of the larvicidal effect in the laboratory by spraying 3 concentrations $\left(D_{1}=4 \times 10^{7}\right.$ spores $/ \mathrm{ml}, D_{2}=4 \times 10^{6}$ spores $/ \mathrm{ml}$ and $D_{3}=4 \times 10^{5}$ spores $\left./ \mathrm{ml}\right)$ of fungal suspensions showed remarkable efficacy, which varied depending on the tested strain, concentration of application and time of exposure. Statistical analysis showed highly significant results on larval mortality rates for both endophytic than the control. After 15 days, dead larvae were mummified. Applications of tested isolates in greenhouse experiments confirmed their marked biological control efficacy than the synthetic insecticide (Emamectin benzoat). Number of mined leaves decreased depending on the contact time of the larvae with the fungal spores.
\end{abstract}

Conclusion: Results suggest that the two endophytic fungi B. bassiana and Clonostachys spp. were very effective entomopathogenic fungi against T. absoluta. Indeed, the present study revealed the pathogenicity of Clonostachys spp. against T. absoluta larvae for the first time.

Keywords: Tuta absoluta, Endophyte, Clonostachys spp., Beauveria bassiana, Larvicidal effect, Entomopathogenic fungi

\footnotetext{
* Correspondence: m-fadhela@netcourrier.com

${ }^{1}$ Biology and Cellular Physiology Department, Faculty of Nature and Life

Science, Blida 1 University, BP270 Blida, Algeria

${ }^{2}$ Protection and Development of Agro-Biological Resources Laboratory,

Faculty of Nature and Life Science, Blida 1 University, BP270 Blida, Algeria

Full list of author information is available at the end of the article
}

\section{Springer Open}

(c) The Author(s). 2021 Open Access This article is licensed under a Creative Commons Attribution 4.0 International License, which permits use, sharing, adaptation, distribution and reproduction in any medium or format, as long as you give appropriate credit to the original author(s) and the source, provide a link to the Creative Commons licence, and indicate if changes were made. The images or other third party material in this article are included in the article's Creative Commons licence, unless indicated otherwise in a credit line to the material. If material is not included in the article's Creative Commons licence and your intended use is not permitted by statutory regulation or exceeds the permitted use, you will need to obtain permission directly from the copyright holder. To view a copy of this licence, visit http://creativecommons.org/licenses/by/4.0/. 


\section{Background}

Pests and phytopathogenic organisms are responsible for numerous damages and diseases infecting market garden crops, fruit and forest trees. The use of chemical pesticides against these organisms has led to multiple consequences on the environment (Ben 2015). Natural products derived from fungi and more especially endophytes represent an important source for the control of crop pests. Endophytic fungi are seen as promising alternatives to substitute chemical fertilizers and pesticides in sustainable and organic farming systems. Different methods of protection against the tomato leaf miner, Tuta absoluta (Meyrick) (Lepidoptera: Gelechiidae) have been reported (Desneux et al. 2010). In terms of biological protection, several auxiliaries have been reported in laboratory conditions, in experimental and production green houses, especially with bedbugs predatory of eggs and young larvae of T. absoluta (Urbaneja et al. 2009). Likewise, several species of Trichogramma parasitoids of T. absoluta eggs were cited (Cabello et al. 2009; Kabiri et al. 2010). In Algeria, Ben Yahia (2015) showed insecticidal activity of Thymus capitatus plant extracts against T. absoluta. Regarding formulations based on entomopathogenic fungi (EPF), many examples are cited, such as Beauveria bassiana (Balsamo) Vuill. (Saranraj and Jayaprakash 2017) and those based on the use of Bacillus thuringiensis (Berliner) (Desneux et al. 2010; Harizia et al. 2019). In Algeria, fewer studies on B. bassiana and Clonostachys spp. (Bainier) have been performed. Pathogenicity of $B$. bassiana to T. absoluta has been demonstrated by Badaoui et al. (2011). Studies carried out on the pathogenicity of Clonostachys spp. against insects are very limited, this study is the first concerning the pathogenicity of Clonostachys spp. on T. absoluta larvae. Clonostachys spp. has been successfully tested as a biological control agent against various pathogens of fungal plants (Mohamed Mahmoud 2017). According to the literature, Clonostachys spp. is nematophagous fungi, which play an important role in the reduction of nematode populations by its antagonistic behavior (Rosalia et al. 2018).

The objective of this study was to evaluate the endophytic fungi; B. bassiana and Clonostachys spp. against T. absoluta larvae under laboratory and greenhouse conditions.

\section{Methods}

\section{Fungal strains}

Fungi used in the present study belong to the collection of the phytopathology laboratory (Department of Biotechnology). The fungal strains $B$. bassiana (Sn182) and Clonostachys spp. (G133), characterized and identified by Mohamed Mahmoud et al. (2017), were isolated from date palm roots growing in Alicante (Spain) (latitude $38^{\circ} 20^{\prime} 42^{\prime \prime} \mathrm{N}$, longitude $0^{\circ} 28^{\prime} 53^{\prime \prime} \mathrm{W}$ and elevation above sea level: $18 \mathrm{~m}=59 \mathrm{ft}$ ). These strains have shown their effectiveness as a biocontrol agent against phytopathogenic fungi and as plant growth stimulants on several plant species (Mohamed Mahmoud 2017).

\section{Preparation of fungal suspensions}

Purification of the strains was carried out in a potato agar culture medium (PDA, Potato Dextrose Agar) (Johnston and Booth 1983). After germination, the stock solutions of the fungal suspensions intended for the infection of T. absoluta larvae were obtained according to the method described by Badaoui et al. (2011). Two drops of Tween 20 were added to $100 \mathrm{ml}$ of these suspensions. The mixture was then stirred for ten minutes in order to let the fungal strains to release their conidiospores. Concentration of each suspension was determined by counting spores, using Malassez cell. Applied concentrations were obtained by successive $1 / 10$ dilutions of the stock solution; $D_{1}=4 \times 10^{7}$ spores $/ \mathrm{ml}, D_{2}=$ $4 \times 10^{6}$ spores $/ \mathrm{ml}$ and $D_{3}=4 \times 10^{5}$ spores $/ \mathrm{ml}$.

\section{Pests}

Tuta absoluta larvae were collected from mined tomato leaves from several varieties cultivated under greenhouse from the Technical Institute of Vegetable and Industrial Cultures (ITCMI) (Staouali, Algeria) (latitude 36.7558, longitude $2.8901836^{\circ} 45^{\prime} 21^{\prime \prime} \mathrm{N}, 2^{\circ} 53^{\prime} 25^{\prime \prime}$ E, elevation above sea level $36 \mathrm{~m}=118 \mathrm{ft}$ ). For their subsequent uses, larvae from the 3rd and 4th instars were placed in sterile glass Petri dishes containing tomato leaves.

\section{Tomato plants}

Seeds of tomato plants (cv. Ebia F1) provided by a private nursery located in (Staouali, Algeria) were used to evaluate the effectiveness efficacy of the endophytic fungi (B. bassiana and Clonostachys spp.). Tomato seeds were disinfected for $20 \mathrm{~min}$ according to Macia-Vicente et al. (2008) method in a solution consisting of sterile distilled water (SDW) and about two to three drops of sodium hypochlorite (2\%). Disinfection step was followed by 3 successive rinses with SDW and draying on sterile filter paper. Germinated seeds were transplanted into pots containing sterile substrate consisting of a mixture of $2 / 3$ sand and $1 / 3$ peat at the rate of 400 g per pot. Pots were kept in a greenhouse at 25 to $30{ }^{\circ} \mathrm{C}$.

\section{Larvicidal effect in laboratory conditions}

Infestation of $T$. absoluta larvae with the tested fungi was carried out by the leaf-dip-bioassay method; described by Cahill et al. (1996). Ten larvae of the 3rd and 4th instars were gently placed in each Petri dish containing filter paper used to absorb the excess suspension and to maintain tomato leaves as fresh as possible. To feed 
the larvae, healthy and young tomato leaves were placed in each box. The same number of larvae was placed in a control dish sprayed with SDW. Three replicates were performed for each concentration as well as for the control. Seven treatments were used in these experiments $\left(12 \mathrm{~m}^{2}\right.$ area of the experiment and $40 \mathrm{~cm}^{2}$ area of individual plot).

\section{Larvicidal effect in greenhouse conditions}

Complete random block experimental was set-up; it consisted of 7 treatments with 20 repetitions for each treatment (140 plants in total). T1: control (without fungal suspension and without T. absoluta), T2: tomato plants + B. bassiana, T3: tomato plants + Clonostachys spp., T4: tomato plants $+T$. absoluta + spray with distilled water, T5: tomato plants $+T$. absoluta + spraying with insecticide (Emamectin benzoat), T6: tomato plants $+T$. absoluta + spraying with B. bassiana, and T7: tomato plants $+T$. absoluta + spraying with Clonostachys spp. On leaves of tomato seedlings 2 months old, fungal suspensions at a concentration of $4 \times 10^{7}$ conidia $/ \mathrm{ml}$ were sprayed with manual sprayer. One week after, on young leaves of each tomato plant, four larvae of different instars were deposited. Plants containing T. absoluta larvae were covered by plastic bags to prevent the spread of larvae. After $24 \mathrm{~h}$ of depositing larvae, a second spraying of tomato plants was carried out with the fungal suspensions, SDW, as well as the chemical insecticide.

\section{In vitro production of protease and chitinase}

In order to check virulence of the strains affiliated to Clonostachys spp. and B. bassiana, proteolytic activity was determined by using skim milk agar medium (Sunish Kumar et al. 2005), and chitinase activity was evaluated on PDA medium where glucose was substituted by chitin as a carbon source (Nihorimbere et al. 2013). Mycelial discs of each tested fungus were deposited on this medium with three replicates. After 2 to 7 days of incubation at $28{ }^{\circ} \mathrm{C}$, the appearance of a clear area around the colony indicated a positive proteolytic activity (Smibert and Krieg 1994), and the synthesis of chitinase was revealed by the rapid growth of fungi.

\section{Statistical analyses}

Obtained results from laboratory and greenhouse experiments were statistically analyzed with the GLM model (General Linear Models) (2012) of the SYSTAT software. Averages of the larvae mortality rate in laboratory conditions and the number of mined leaves in greenhouse conditions were recorded and analyzed.

\section{Results}

In laboratory conditions, an increase in mortality rate of T. absoluta larvae varied according to time of exposure and fungal strains concentrations. Mortality rate of larvae infected by both fungal strains Clonostachys spp., and B. bassiana at different doses: $D_{1}=4 \times 10^{7}$ spores/ $\mathrm{ml}, D_{2}=4 \times 10^{6}$ spores $/ \mathrm{ml}, D_{3}=4 \times 10^{5}$ spores $/ \mathrm{ml}$, negative control $D_{0}=0$ spores $/ \mathrm{ml}$ was evaluated after 24, 48, and $72 \mathrm{~h}$ after infestation (Table 1). After $24 \mathrm{~h}$, mortality rate of T. absoluta larvae was high by using $D_{1}$ concentration of Clonostachys spp., and increased to $90 \%$, while it was low at low concentrations, where it reached $35 \%$ for $D_{2}$ and $30 \%$ for $D_{3}$ concentrations. Larval mortality rate was high $80 \%$ when infection was done by $D_{1}$ concentration of $B$. bassiana, and reached $40 \%$ by $D_{2}$ and $D_{3}$ concentrations (Table 1 ). For the control, larvae sprayed only with SDW recorded a low larval mortality of $10 \%$. After $48 \mathrm{~h}$, larvae inoculated with the $D_{1}$ concentration of Clonostachys spp., no changes were observed in mortality rates of larvae than the first day (90\%), while for the other concentrations mortality rates reached $70 \%$ for $D_{2}$ and $60 \%$ for $D_{3}$. Regarding $D_{1}$ suspension of $B$. bassiana, mortality rate reached its maximum of $100 \%$, however, for the other concentrations, it increased and attained $65 \%$ for $D_{2}$ and $50 \%$ for $D_{3}$. A small increase in mortality rate was observed for larvae sprayed with SDW (Table 1). After $72 \mathrm{~h}$ following the infection, the applied $\mathrm{D}_{1}$ concentration of Clonostachys spp., completely killed the larvae (100\%), while this rate increased at the $D_{2}$ concentration and reached 80 and $70 \%$ with $D_{3}$ concentration. The highest death rate value of $100 \%$ was observed by $D_{2}$ concentration of $B$. bassiana. On the other hand, for the $D_{3}$ concentration, a rate of only $55 \%$ was obtained. For the control, a slight increase to $20 \%$ in the larval mortality rate was noticed (Table 1).

The larvicidal effect of the two endophytic fungi $\mathrm{Clo}$ nostachys spp. and B.bassiana compared to SDW (control) was highly significant $(P=0.000)$ on the variability in the mortality rate of $T$. absoluta larvae after 3 days

Table 1 Mortality rates (\%) of Tuta absoluta larvae after application of suspensions of entomopathogenic fungi

\begin{tabular}{llll}
\hline $\begin{array}{l}\text { Treatments (spores/ml)/ } \\
\text { times after infestation }\end{array}$ & \multicolumn{3}{l}{ Mortality rates (\%) } \\
\cline { 2 - 4 } $\mathbf{2 4 \mathbf { h }}$ & $\mathbf{4 8 ~ \mathbf { ~ }}$ & $\mathbf{7 2 ~ \mathbf { ~ }}$ \\
\hline Beauveria bassiana & 80 & 100 & 100 \\
$D_{1}=4 \times 10^{7}$ & 40 & 65 & 100 \\
$D_{2}=4 \times 10^{6}$ & 40 & 50 & 55 \\
$D_{3}=4 \times 10^{5}$ & & & \\
Clonostachys spp. & 90 & 90 & 100 \\
$D_{1}=4 \times 10^{7}$ & 35 & 70 & 80 \\
$D_{2}=4 \times 10^{6}$ & 30 & 60 & 70 \\
$D_{3}=4 \times 10^{5}$ & & & \\
Control & 10 & 13 & 20 \\
$D_{0}=0$ &
\end{tabular}


following infection. For the two fungi, the highest concentration $\left(D_{1}\right)$ hit the target and killed more effectively the larvae than the lowest concentration suspensions $\left(D_{2}\right.$ and $D_{3}$ ). One week after infection, live larvae developed inside the Petri dishes sprayed with the two fungi suspensions $D_{2}$ and $D_{3}$ and evolve into adults. From obtained results, as a function of time, especially for $D_{2}$ and $D_{3}$, the fungus Clonostachys spp. showed a relatively progressive efficacy, while for the highest $D_{1}$ concentration, total larval mortality was observed after 3 days of infection. The larvae covered with the mycelium and spores of Clonostachys spp. after 20 days of inoculation, they gave an appearance of a mummy (white muscardine).

Under greenhouse conditions, $24 \mathrm{~h}$ after depositing the larvae of $T$. absoluta on tomato leaves, the symptoms appeared clearly in young leaves, which were sprayed a week before by the suspensions at $D_{1}$ concentration of Clonostachys spp., B. bassiana as well as with SDW; on the other hand, fewer symptoms occurred on plants treated with the insecticide (Table 2). After a period of $24 \mathrm{~h}$, following the second spraying of the studied fungi or chemical preparations, there was an increase in the number of infected (mined) leaves, especially for SDW and the suspension of Clonostachys spp. The average of infected leaves was three (Table 2). After $48 \mathrm{~h}$ of the second spraying of the fungal suspensions along with the insecticide, the number of infected leaves remained constant unlike for SDW, where the number had undergone a gradual increase to five infected leaves (Table 2). After a period of $72 \mathrm{~h}$ for the second spraying, all larvae were killed; the average number of leaves sprayed with SDW had reached its maximum to nine and the number of leaves treated with B. bassiana preparation and chemical insecticide remained constant. For the fungal preparation of Clonostachys spp., the average of infected leaves increases to five (Table 2).

For the three treatments not inoculated with the larvae of $T$. absoluta and sprayed with the different suspensions of Clonostachys spp., and B. basiana as well as with SDW, the plants were healthy, showing no symptoms of infection, and showed a very good growth. After
6 days of application of the fungal preparations, the killed larvae were covered by a white powder, corresponding to the mycelium and the spores of the fungi tested. Results obtained from the comparative study of the number of infected leaves after 3 days of tracking showed that the fungus $B$. bassiana was more effective than Clonostachys spp. In vitro production test of protease and chitinase enzymes were studied; appearance of a clear halo all around the fungal fragment means that there were a production of protease from Clonostachys spp. and B. bassiana. Mycelial growth of both fungi on PDA medium in the presence of chitin indicated synthesis of chitinase.

\section{Discussion}

The present study showed that larvicidal effects were significantly observed in laboratory and in greenhouse conditions by using the two endophytic fungi, B. bassiana and Clonostachys spp. A significant effect of fungal suspensions on larval mortality whatever the concentrations used was found. It is recognized that the mortality of insects infected with EPF depends on the number of spores coming into contact with the insects (Steinkraus and Tugwell 1997). The same results were observed by other authors (Torres-Gregorio et al. 2009; Pires et al. 2010) and thus, make it possible that the isolates studied had a pathogenic action on larvae of the tomato leaf miner. Pathogenicity of $B$. bassiana against $T$. absoluta has been demonstrated by several studies (Badaoui et al. 2011; Tadele and Emana 2017). Garrido-Jurado et al. (2020) reported that the EPF can reduce fecundity and fertility of insect. According to a previous study, $B$. bassiana was shown to be an efficient fungus in biocontrol of soil inhabiting phytopatogenic fungi (F. oxysporum f.sp. lycopersici, F. oxysporum f.sp. albedinis and Gaeumannomyces graminis var. tritici) (Mohamed Mahmoud 2017). B. bassiana produces very toxic metabolites with several properties, like antibacterial, antifungal, cytotoxins such as beauvericin and basinoloide, as well as insecticides produced during the breakdown of the cuticle of host insects and infection of the pathogen target. These metabolites are involved in the infection of insect

Table 2 Number of infected leaves after the spraying of the different treatments

\begin{tabular}{|c|c|c|c|c|}
\hline \multirow[t]{3}{*}{ Treatments } & \multicolumn{4}{|c|}{ Number of infected leaves \pm standard error } \\
\hline & \multicolumn{4}{|c|}{$\begin{array}{l}\text { Times after the second spraying the deposit of } \\
\text { the different treatments larvae on tomato }\end{array}$} \\
\hline & $24 \mathrm{~h}$ & $24 \mathrm{~h}$ & $48 \mathrm{~h}$ & $72 \mathrm{~h}$ \\
\hline Tomato plants + Tuta absoluta + sprayed with Beauveria bassiana & $2 \pm 1.18$ & $2 \pm 1.75$ & $2 \pm 2.83$ & $2 \pm 3.17$ \\
\hline Tomato plants $+T$. absoluta + sprayed with Clonostachys spp. & $2 \pm 1.12$ & $3 \pm 2.03$ & $3 \pm 2.15$ & $5 \pm 3.16$ \\
\hline Tomato plants $+T$. absoluta + sprayed with insecticide & $1 \pm 0.60$ & $1 \pm 0.94$ & $1 \pm 0.88$ & $1 \pm 0.94$ \\
\hline \multicolumn{5}{|l|}{ Control } \\
\hline Tomato plants $+T$. absoluta + sprayed with distilled water & $1 \pm 0.85$ & $3 \pm 1.61$ & $5 \pm 2.76$ & $9 \pm 3.95$ \\
\hline
\end{tabular}


hosts including chitin and other products (Alexopoulos et al. 1996).

Studies carried out on the pathogenicity of Clonostachys spp. against insects are very limited. Therefore, it was difficult to compare the results of this study with other studies, especially for $T$. absoluta larvae. This study is the first to show that Clonostachys spp. caused the mortality of $T$. absoluta larvae. They have been successfully tested as biological control agents against various pathogens of fungal plants (James and Sutton 1996). Mohamed Mahmoud (2017) showed that Clonostachys spp. was a very effective antagonist against soil-based phytopathogenic agents and its effect has been remarkable by the phenomenon of mycoparasitism activity. According to Rosalia et al. (2018), Clonostachys spp. is a nematophagous fungus, which plays an important role in the reduction of nematode populations through their antagonistic behaviors. There are many biotic and abiotic constraints on the ability of fungi to infect their hosts under plant conditions, among which are microbial antagonists, temperature, and humidity (Inglis et al. 2001). The use of EPF as a microbial control agent depends on the appropriate inoculum, optimally formulated and time applied to a susceptible host (Badaoui 2017). No negative effects were observed on the plants inoculated only with EPF explaining that they have no phytotoxic activity (Zimmermann 2007). Production of protease and chitinase was consistent with previous works which have showed that these enzymes were responsible for the penetration of the fungus through the cuticle of the larvae. Following the works of Saranraj and Jayaprakash (2017), EPF penetrate and dissolve the insect cuticle using a mechanical pressure and a mixture of enzymes...

\section{Conclusion}

Two fungal endophytes Clonostachys spp. and B. bassi$a n a$, tested under laboratory and greenhouses conditions, caused significant mortality of T. absoluta larvae than the control. However, there were variations in the mortality rates among the concentrations of the fungal isolates. The study showed that B. bassiana was more effective than Clonostachys spp. The results remain very satisfactory and significant, despite the fact that the chemical insecticide was more effective than the fungal suspensions used in practice. Further studies under field conditions should be undertaken to evaluate effectiveness of experimental mycopesticide in the management of T. absoluta.

\section{Abbreviations}

EPF: Entomopathogenic fungi; PDA: Potato dextrose agar; SDW: Sterile distilled water; GLM: General linear models

\section{Acknowledgements}

Not applicable

\section{Authors' contributions}

$F M, R B, B B, F T$, and ZK designed and executed the experiment. LT analyzed the data. FM and ZK wrote the manuscript. All authors read, reviewed, and approved the final manuscript.

\section{Funding}

There is no funding source to be declared for this study.

Availability of data and materials

All data generated or analyzed during this study are included in this published article.

Ethics approval and consent to participate

Not applicable

\section{Consent for publication}

Not applicable

\section{Competing interests}

The authors declare that they have no competing interests.

\section{Author details}

${ }^{1}$ Biology and Cellular Physiology Department, Faculty of Nature and Life Science, Blida 1 University, BP270 Blida, Algeria. ${ }^{2}$ Protection and

Development of Agro-Biological Resources Laboratory, Faculty of Nature and Life Science, Blida 1 University, BP270 Blida, Algeria. ${ }^{3}$ Biotechnology Department, Faculty of Nature and Life Science, Blida 1 University, BP270 Blida, Algeria. ${ }^{4}$ Djillali Liabès University, Sidi Bel Abbès, Algeria.

Received: 11 December 2020 Accepted: 17 February 2021

Published online: 25 February 2021

\section{References}

Alexopoulos CJ, Mims CW, Blackwell M (1996) Introductory mycology. Wiley, New York

Badaoui MI (2017) Contribution à l'étude de la dynamique des populations de Tuta absoluta Meyrick (Lepidoptera; Gelechiidae) et essais de contrôle biologique Sur la culture de tomate Universite Abdelhamid Ibn Badis Mostaganem, Algérie

Badaoui MI, Berkani A, Lotmani B (2011) Les entomopathogènes autochtones, nouvel espoir dans le contrôle biologique de Tuta absoluta Meyrick 1917 (Lepidoptera: Gelechiidae) en Algérie. Faunistic Entomol 63(3):165-169

Ben AS (2015) Activités antimicrobiennes et insecticides de Thymus capitatus, Daucuscrinitus et Tetraclinis articulata sur la mineuse Tuta absoluta (Meyrick) et la microflore pathogène de la tomate Lycopersicum esculentum Universite Abou-Bakr Belkaid Tlemcen, Algérie

Cabello T, Gallego JR, Vila E, Soler A, del Pino M, Carnero A, Hernández-Suárez E, Polaszek A (2009) Biological control of the south American tomato pinworm, Tuta absoluta (Lep.: Gelechiidae), with releases of Trichogrammaachaeae (Hym.: Trichogrammatidae) in tomato greenhouses of Spain. IOBC/WPRS Bul 49:225-230

Cahill M, Gorman K, Day S, Denholm I, Elbert A, Nauen R (1996) Baseline determination of resistance to imidacloprid in Bemisia tabaci (Homoptera: Aleyrodidae). Bull Entomol Res 86:343-349

Desneux E, Wajnberg AG, Wyckhuysk G, Burgio S, Arpaia CA, Narvaez-Vasquez JG, Lez-Cabrera DC, Ruescas E, Tabone J, Frandon J, Pizzol C, Poncet T, Cabello AU (2010) Biological invasion of European tomato crops by Tuta absoluta: ecology, geographic expansion and prospects for biological control. J Pestic Sci 83:197-215

Garrido-Jurado I, Montes-Moreno D, Sanz-Barrionuevo P, Quesada-Moraga E (2020) Delving into the causes and effects of entomopathogenic endophytic Metarhizium brunneum foliar application-related mortality in Spodoptera littoralis larvae. Insects 11:429. https://doi.org/10.3390/insects11070429

Harizia A, Benguerai A, Boukhari Y (2019) Larvicidal activity of Bacillus thuringiensis kurstaki against Tuta absoluta (Lepidoptera: Gelechiidae). Lebanese Sci J 20(3):352-362

Inglis GD, Goettel MS, Butt TM, Strasser H (2001) Use of hyphomycetous fungi for managing insect pests. In: Butt TM, Jackson C, Magan N (eds) Fungi as 
biocontrol agents: Progress, problems and potential. CABI, Wallingford, pp 23-69

James TDW, Sutton JC (1996) Biological control of Botrytis leaf blight of onion by Gliocladium roseum applied as sprays and with fabric applications. Eur J Plant Pathol 102:265-275

Johnston A, Booth C (1983) Plant pathologist's pocket book, 2nd edn. Commonwealth Mycological Institute, Surrey

Kabiri F, Vila E, Cabello T (2010) Trichogrammaachaeae: an excellent biocontrol agent against Tuta absoluta. Sting Newslett Biol Control 33:5-6

Macia-Vicente JG, Jansson HB, Mendgen K, Lopez-Liorca LV (2008) Colonization of barley roots by endophytic fungi and their reduction of take-all caused by Gaeumannomyces graminis var. tritici. Can J Microbial 54:600-609

Mohamed Mahmoud F (2017) Activités biologiques de champignons endophytes isolés du palmier dattier (Phoenix dactylifera L.) Ecole Nationale Supérieure d'Agronomie El Harrach, Algérie

Mohamed Mahmoud F, Krimi Z, Maciá-Vicente JG, Brahim Errahmani M, LopezLlorca LV (2017) Endophytic fungi associated with roots of date palm (Phoenix dactylifera) in coastal dunes. Rev Eberroam Mycol 34(2):116-120

Nihorimbere V, Kakana P, Sindayigaya E (2013) Isolation of Bacillus strains from the rhizosphere of tomato and there in vitro antagonistic effects against phytopathogenic fungi. Global Adv Res J Microbiol 2:65-71

Pires LM, Marques EJ, Oliveira JV, Alves SB (2010) Selection of isolates of entomopathogenic fungi for controlling Tuta absoluta (Meyrick) (Lepidoptera: Gelechiidae) and their compatibility with insecticides used in tomato crop. Neotrop Entomol 39(6):977-984

Rosalia RM, Mendoza-de-Gives P, Aguilar-Marcelino L, López-Arellano ME, Gamboa-Angulo M, Rosas-Saito GH, Reyes-Estébanez M, García-Rubio VG (2018) In vitro lethal activity of the nematophagous fungus

Clonostachysrosea (Ascomycota: Hypocreales) against nematodes of five different taxa. Biomed Res Int 3501827:7. https:/doi.org/10.1155/2018/3501827

Saranraj P, Jayaprakash A (2017) Agrobeneficial entomopathogenic fungi Beauveria bassiana: indo. Asian J Multidiscipl Res 3(2):1051-1087. https://doi. org/10.22192/iajmr.2017.3.2.4

Smibert RM, Krieg NR (1994) Phenotypic characterization. In: Gerhardt P, Murray RGE, Wood WA, Krieg NR (eds) Methods for general and molecular bacteriology, American Society of Microbiology, Washington DC, pp 611-654

Steinkraus DC, Tugwell NP (1997) Beauveria bassiana (Deuteromycotina: Moniliales) effects on LJ'gus lineolaris (Hemiptera:Miridae). J entomol Sei 32:79-90

Sunish Kumar R, Ayyadurai N, Pandiaraja P, Reddy AV, Venkateswarlu Y, Prakash O, Sakthivel N (2005) Characterization of antifungal metabolite produced by a new strain Pseudomonas aeruginosa PUPa3 that exhibits broad-spectrum antifungal activity and biofertilizing traits. J Appl Microbiol 98:145-154

Tadele S, Emana G (2017) Entomopathogenic effect of Beauveria bassiana (Bals.) and Metarrhizium anisopliae (Metschn.) on Tuta absoluta (Meyrick) (Lepidoptera: Gelechiidae) larvae under laboratory and glasshouse conditions in Ethiopia. J Plant Pathol Microbiol 8:411. https://doi.org/10.4172/2157-74 71.1000411

Torres-Gregorio J, Argente J, Diaz MA, Yuste A (2009) Applicacion de Beauveria bassiana en la lucha biologica contra Tuta absoluta. Agricola Vergel Fruticultura Horticultura Floricultura 326:129-132

Urbaneja H, Monto'n O, Molla (2009) Suitability of the tomato borer Tutaabsoluta as prey for Macrolophus caliginosus and Nesidiocoristenuis. J Appl Entomol 133:292-296

Zimmermann G (2007) Review on safety of the entomopathogenic fungi Beauveria bassiana and Beauveria brongniartii. Biocontrol Sci Tech 17:1-44

\section{Publisher's Note}

Springer Nature remains neutral with regard to jurisdictional claims in published maps and institutional affiliations.

\section{Submit your manuscript to a SpringerOpen ${ }^{\circ}$ journal and benefit from:}

- Convenient online submission

- Rigorous peer review

- Open access: articles freely available online

High visibility within the field

- Retaining the copyright to your article

Submit your next manuscript at $\boldsymbol{\nabla}$ springeropen.com 